\title{
Effect of an Educational Training on Mothers' Competency Level for Managing the Children with Autism
}

Rahma SolimanBahget: Professor of Pediatric Nursing Faculty of Nursing, Tanta University

Ebtisam Mohamed El Sayed: Professor of Pediatric Nursing, Faculty of Nursing, Tanta University

Mohammed Abd El Hakeem Seleem: Assistant Professor of Psychiatric medicine, Faculty of medicine, Tanta University

Noha El-Sayed Shams El Deen, Master of Pediatric Nursing, Faculty of Nursing, Tanta University

\begin{abstract}
Autism is a pervasive developmental disorder characterized by impaired social and communication skills as well as restrictive or repetitive patterns of behavior. These impairments significantly influence the manner in which children with autism interact with the environment. Competency level of parents affects their care and management for autistic child. Aim: This study aimed to determine the effect of an educational training on mother's competency level for managing the children with autism. Materials and Method: This study was conducted on fifty mothers and their autistic children at Child Psychiatry out-patient clinic in Psychiatry and Neurology Center in Tanta University. Four tools were used: Biosociodemographic, knowledge and attitude structured interview schedule, Social Communication questionnaire, Parent sense of competency scale, and Mothers' practices structured interview schedule. The data were collected before, immediately after and 3 months after implementation of educational training. Results: The main results revealed significant increase in mother's competency level, decreased emotional stress and increased maternal satisfaction regarding parenting role and care of their autistic children. Conclusion: there was improvement in mother's competency level for managing their children with autism. This study recommended that parents should be actively involved in their children's intervention. Continuous health education programs are necessary to improve parenting approaches and coping strategies.
\end{abstract}

Key words: mother's competency level, educational training, autism management 


\section{Tanta Scientific Nursing Journal}

\section{Introduction}

Autism spectrum disorder is a serious developmental disability that typically appears during the first three years of child's life as a result of a neurological disorder affecting the function of the brain. Autism also is a lifelong disability that occurs in all racial, ethnic and social groups $^{1}$.The estimated prevalence of autism has significantly increased in recent years. It is currently considered to have a prevalence of $1 \% .{ }^{(1)}$ The prevalence in the United States is estimated to be 1 in 68 (at age 8) according to Center for Disease Control and Prevention 2014. ${ }^{(2)}$ The gender ratio of children with autism is $4: 1$ (male to female). The prevalence rate of autism in Egypt was one child every 875, (3) and constitute $33.6 \%$, among children with developmental disorders in Egypt. ${ }^{(4)}$ The causal mechanisms of autism are not known, it is likely to have multiple etiologies; including genetic causes which may be the most significant causes. ${ }^{(5)}$ The risk of autism is also associated with several environmental factors that include prenatal factors as advanced age in one or both parents, diabetes, bleeding, and use of psychiatric drugs during pregnancy. Infection-associated immunological events in early pregnancy may also affect neural development. Postnatal factors include immune system abnormalities, allergies, and exposure of children to drugs, vaccines and infection. ${ }^{(6)}$

The disorder is characterized by a wide variety of possible symptoms such as communication skill deficits; which may include a delay or absence of spoken language. Children that do develop speech may not initiate or sustain conversations with others. Lack of social interaction may be manifested through impairment in social interaction, failure to create peer relationships, and lack of spontaneous or pretend play. The children with autism are usually present with restricted, repetitive, and stereotyped patterns of behavior, interests, and activities, and may exhibit high levels of aberrant behaviors such as tantrums, aggression and self injury. Children with autism may also have impaired cognitive skills and sensory perception which affect the child's ability to focus, pay attention and learn. ${ }^{(7)}$

Autism cannot be cured. The main management of autism is educational and behavioral interventions as social skills interventions which focus on enhancing social behavior and competence in children with autism. Communication skills intervention is one of the greatest challenges for families. Parents must be 
able to teach their autistic children the communication skills by which they can express their wants and needs and share information. (8) Behavioral interventions focus on behaviors commonly associated with autism. These approaches attempt to ameliorate symptoms such as tantrums, self-injury and aggression. (9) Play interventions use interactions between children and adults to improve imitation, joint attention skills or the ability of the child to engage in symbolic play. ${ }^{(10)}$ Massage intervention is a global treatment for the child. It can be delivered by parents to their children after appropriate training and support. It has been shown to improve developmental measures in young children with autism when given daily. This Intervention can be used to improve disturbances of sensory impairment, digestion, sleep and strengthen overall health of autistic children. ${ }^{(11)}$

Autism is a complex, and children with autism need varying levels of lifelong care. ${ }^{(12)}$ Caregivers play a vital role in the care giving and a central part of the lives of children with autism. Caregivers are an instrumental partner taking active participation in affecting the nature and direction of care process of autistic children. ${ }^{(13)}$ Parental self-efficacies refer to parents' perceptions of their capability in the role of caring for and positively nurturing the growth and development of their children. Parental self-efficacy has a direct impact on the behaviors. ${ }^{(14)}$ Primary caregivers' need for effective and efficient professional services to be better able to meet the needs of the family and help them cope with taking care of a child with autism at home and within the community. Parent education and support needs to improve the family's quality of life. Parental involvement in the intellectual, social, and emotional development of children with autism is vitally important to their growth. Once trained, parents can act as co-therapists, shaping behavior to reduce negative behaviors in daily life. Parent training interventions also have secondary targets of improving parental feelings of self efficacy and decreasing parental stress. $^{(15)}$

The most significant role of nurse in autism recognition and diagnosis is education. The nurse must be able to familiarize the combination of symptoms associated with autism to the parents. This places nurses at a critical juncture, because they must be increasingly knowledgeable, understanding and supportive of the parents and children afflicted with this condition and facilitating development and learning, promoting socialization and 
reducing maladaptive behaviors. The nurse is the coordinator of therapies and interventions that meet the specific needs of individual children. ${ }^{(16)}$

The number of children diagnosed with autism has dramatically increased in the past few years and it became the most commonly diagnosed childhood brain disorders ${ }^{(2)}$. The prevalence rate of autism in Egypt is one every 870 Egyptian children has autism ${ }^{(5)}$. This means that a considerable number of parents are directly involved in caring of the children with autism. Autistic children need special attention and care borne by parents. The inability of the parents to successfully play this role may frustrate them and deprive the children from developing better skills. Parent education is an important component of autism intervention, as it can provide positive outcomes for parents and, in turn, their children. This study investigated the impact of parent education on parents' sense of competence to manage their autistic children.

\section{Aim of the study}

The aim of this study was to determine the effect of an educational training on mother's competency level for managing the children with autism.

\section{Research Hypothesis}

The maternal educational training was improved mother's knowledge, practices, and attitudes and mothers' competency level for managing the children with autism

\section{Materials and Method}

\section{Research Design:}

A quasi experimental research design was used

\section{Setting:}

The study was conducted at Child Psychiatry out-patient clinic in Psychiatry and Neurology Center at Tanta University.

\section{Subjects:}

Fifty mothers and their autistic children were included in the study with no special criteria regarding their educational level, occupation or residence area. The children had the following criteria: Age ranged from 4 -12 years, both sexes and free from chronic physical illnesses.

\section{Tools of data collection:}

Tool I: Biosociodemographic, knowledge and attitude structured interview schedule:

It was developed by the researcher to obtain biosociodemographic data of the mothers and their autistic children, and assess mothers' knowledge and attitude about autism. 


\section{Part I:}

\section{Biosociodemographic characteristics of} the mothers:

Mothers' age, level of education, occupation and residence. Family type, income, size, history of autism and consanguinity

\section{Characteristics of children:}

Child age, sex, birth order and educational level

Child's medical history which includes: autism related data, degree of disability, duration and age when autism discovered, pregnancy and first 3 years of life problems.

Part II: Mothers' knowledge and attitude toward autism:

\section{Mother 's knowledge about autism :}

It was developed by the researcher to assess mothers' knowledge about autism; meaning of autism and its causes, common age of autism occurrence , manifestation of autism and effect of autism on the child, diagnosis, duration of treatment, needs of the child, treatment approaches, side effects of drugs, play and massage management.

It included 13 items of multiple choice questions by using the following scoring system; A correct \& complete response was scored (2), incorrect \& incomplete (1), incorrect or don't know (0) then the total score was calculated and converted into a percent score. Mothers' knowledge was considered good when the total score was $(70 \%)$ or more, fair when it was from $50 \%$ - 69\% and poor knowledge scored less than $50 \%$.

\section{B- Mothers' attitude toward autism:}

This was measured using a scale developed by the researcher based on reviewing scales by Donenberg (1994), and Abidin $(1995)^{(17,18)}$ and modified by the researcher to suit the study culture. It consisted three categories; Mothers' attitude toward nature of the disease and its effect on the child (9 statements), mothers' attitude toward consequences of autism on the family life (8 statements), and mothers' feelings towered autistic child including stress and frustration feeling (10 statements)

Each item was rated on a 3 - point likert scale, the mothers were asked to select the answer on each item according to how accurately the items described their attitude and feelings toward autistic child and autism. Each positive statement was scored as follows: Agree $=2$, Uncertain $=1$ and Disagree $=0$, the scoring was reversed for negative statements. 


\section{Tool II: Social Communication} questionnaire:

It was developed by Rutter \& Lord 2003. (19) This scale was used by the researcher to assess severity of autism regarding social interaction, communication and the repetitive, stereotyped patterns of behavior. It included 40 items, each item is rating on 2-point Likert scale, each item was either yes (1 grade) or no ( zero grade ), the total scores was 40 grades. The autism severity was categorized as: $\leq 15=$ no autism, 15-22= mild , 23- 31= moderate and $32-40=$ sever autism.

\section{Tool III: Parenting sense of competence} scale:

This was measured by using a scale developed the researcher based on reviewing scales originally developed by Johnston 2000 and Ruble $2005^{(20,21)}$ and modified by the researcher and used to assess feelings of competence as a parent and feelings of comfort and value in that role. It consisted of three subscales:

The efficacy subscale: assessed the degree of acquired the necessary skills to enhancing their child development (10 items)

The responsiveness subscale: assessed parent's interaction and responsiveness toward their children (6 items).
The Satisfaction subscale: assessed parents' affective perceptions about their value of and comfort in the parenting role (8 items).

Mothers' Responses were rated on a 3point Likert scale; agree $=2$, uncertain $=1$ and disagree $=0$ score. Items within each subscale were summed and converted into a percentage. The mother's competency level of care was considered low when the total score was less than (50\%), moderate when it was from 50\%- 69\%, and high if total scores was $70 \%$ or more.

\section{Tool V: Mothers' practices structured} interview schedule:

It was developed by the researcher to assess mothers' practices in caring for their autistic children, it included;

1-Reported practices: It included five parts as the following:

Communication skills: it was used to assess mothers' practices to improve verbal and non verbal communication skill of the child, included (12) items.

Social skills: it was used to assess mothers' practices to improve child's Social interaction skills as interaction with others, eye contact and imitation, it included (19) items.

Behavior problem : it was used to assess mothers' practices to improve behavior 
problem of the child as using reward, time out and management of maladaptive behavior as tantrums and aggression, it included (17) items.

Play skills: it was used to assess mothers' practices to improve using play activities as imitation of play activates, sharing play with others and choosing suitable toys for the child, it included (20) items.

\section{Physical care skills:}

It was used to assess mothers' practices related the activities of daily living as hygienic care, feeding, elimination, nutritional problems, sleep problems and safety environment (95 items)

Observed practices : It included three parts related to the following:

Strength the speaking organs: assess mothers' related to doing simple exercises for speaking organs of the child, it included (14) items.

Motor skills: assess mothers' management to improve fine and gross motor skills of the child, it included (14) items.

Massage technique: assess mothers' while doing massage for their children. It includes preparation before massage and techniques of massage, it included (20) items.

Scoring system; each item was scored as; correct or complete done $=1$, incorrect or not done $=0$. The mothers' practices was considered good when the total score was $70 \%$ or more, fair from $50 \%$ to $>69 \%$ and poor if the total score was less than $50 \%$

\section{Content validity}

The study tools had been tested for content validity by five experts in the field of pediatric nursing and modifications carried out accordingly.

\section{Ethical and legal considerations:}

The agreement for participation in the study was taken from subjects after the purpose of the study was explained to them. Before data collection, the mothers and their autistic children were informed about the aim and the nature of the study which didn't cause any harm or pain. Also they were assured that the information would remain confidential and used for the purpose of research only.

\section{Pilot study}

A pilot study was carried out to test the clarity, and applicability of the tools, the required modification was done. A total of 5 subjects were recruited for the pilot study and excluded from total sample.

\section{Procedure}

An actual field work was carried out over a period of one year from November 2014 to October 2015. The following detailed description of the steps involved in the development, implementation and evaluation of the educational training; 


\section{Preparatory phase :}

An oral approval for data collection was obtained from administrators responsible for the Child Psychiatry out-patient clinic in Psychiatry and Neurology Center at Tanta University for carrying out the study. The program was designed by the researcher after review of the literature to meet mothers' knowledge and practices deficits. The content was prepared according to the mothers' level of understanding.

\section{The implementation phase:}

The total number of the sample 50 mothers and their children, they were divided into 5 groups 10 mothers in each group. The educational training was introduced to each group separately 2 session / week, the total number of session was 10 session, each session was presented for one hour for knowledge and practices . The content of knowledge involves items about meaning of autism and its causes, common age of autism occurrence, manifestations of autism and effect of autism on the child, diagnosis, duration of treatment, needs of the child, treatment approaches, side effects of drugs, play and massage management. The content of practice was about communication skills, social skills, behavior problem, play skills motor skills, massage technique and physical care skills.

In the first session; pre test was done and objective of the educational training were explained to the mothers. The teaching strategy includes lectures, discussion, role playing, data show, video, actual situation and demonstration. Also handouts of the educational training were given to the mothers.

\section{Evaluation phase}

Evaluation of the effectiveness of the educational training was done immediately after and three months after the educational training implementation by reassessment using the same questionnaires (post test).

\section{Statistical Analysis}

The collected data was organized, tabulated and statistically analyzed using SPSS software statistical computer package version 19. For quantitative variables, mean and standard deviation were calculated. The number and percentage distribution was calculated. Fisher exact test (p) was used to compare observations before and after training application. Significance was adopted at $p<0.05$ for interpretation of results of tests of significance. 


\section{Results}

Table (1): shows that nearly two thirds of the studied mothers $(62 \%)$ were in the age group of 25 to less than 35 years, $48 \%$ had university education, $64 \%$ were not working and the most of them $(80 \%)$ were resident in urban areas.

Table (2): shows the studied children according to their sociodemographic characteristics. It was found that the age of the autistic children ranged from 4-12 years, with a mean of $6.28 \pm 2.48$.years. More than half of the them $(52 \%)$ were in the age group of 4 to less than 6 years, and less than three fourth of them (74\%) were males. The table shows that when autism was discovered, the age of studied children was $2-5$ in $72 \%$ of them

Table (3): Shows the effect of the educational training on the total mean score of knowledge of mothers about autism through the study period. It was found that, before the educational training $78 \%$ of the mothers had poor knowledge about autism while $82 \%$ and $80 \%$ of them had good knowledge immediately after and 3 months after educational training respectively. There was significant improvement in the knowledge of studied subjects $(\mathrm{P}>0.05)$.

Table (4): It was found that the percentage of mothers according to their practices were $78 \%$ good, $10 \%$ avarge, $12 \%$ poor after the implementation of the training program compared to $6 \%$ good, $32 \%$ average, $62 \%$ poor before the program. The difference was statistically significant where the mean score of practices were (71.2 \pm 56.2$)$ before the training, $(162.2 \pm 50.1)$, after and 3 months after the educational training $(\mathrm{P}<0.05)$.

Table (5) \& Figure (7): Illustrate the effect of the educational training on the total mean score of attitudes of mothers about autism. Regarding nature of autism and child problems the total mean score increased from $(6.72 \pm 6.91)$ before the educational training to $(8.80 \pm 6.91)$ after training. Mother's attitude toward family problems was $(6.84 \pm 6.01)$ before training which increased to $(7.64 \pm 6.42)$. This table also shows that stress feelings of the mothers toward autism consequences were $(13.96 \pm 7$. 21) which decreased to $(11.10 \pm 7.21)$ after the educational training implementation.

Table (6): Represents the effect of the educational training on mothers' competency level regarding total mean score of self efficacy, response and satisfaction. Regarding mothers' self efficacy, the total mean score increased from (10.24 \pm 8.08$)$ before the training program to $(21.26 \pm 8.34)$ after program. 
The total mean score of mothers' response to the needs of their autistic children was $(8.42 \pm 5.69)$ before training which increased to $(15.66 \pm 4.63)$ immediately after educational training. This table also shows that the total mean of mothers' satisfaction regarding their parenting role before educational training was $(8.14 \pm 5.84) \quad$ which increased to $(14.88 \pm 5.61) \quad$ immediately after educational training implementation.

Table (7): The table shows that there was a significant correlation between the competency level of care with knowledge, practice and attitude before, after and 3 months after educational training $(\mathrm{p}<0.05)$.

Table (8): Represents the relationship between the mothers' competency level of care and their sociodemographic characteristics. As regard the age of the mothers, the age group from 30 to less than 40 years had the highest mean scores of competency level of care in after and 3 months post program (69.14 \pm 1.46 and $69.14 \pm 1.57$ respectively). There was significant increase in the competency level among the different age groups of the studied mothers.

Table (9): Represents the relationship between the mothers' competency level of care and sociodemographic characteristic of their children. In relation to the disease severity, it was observed that the highest mean scores of competency level of the mothers was with children who had mild degree $(69.16 \pm 1.60)$ than moderate $(67.12 \pm 2.50)$ and severe degree of disease (39.32 \pm 15.73$)$ after the program, the improvement was statistically significant where $\mathrm{p}<0.05$.

Table (1): distribution of the studied mothers According to their Sociodemographic characteristics

\begin{tabular}{|l|c|c||}
\hline Mothers characteristics & No & $\%$ \\
\hline Mother age & 31 & 62.0 \\
$25->35$ & 12 & 24.0 \\
$35-45$ & 7 & 14.0 \\
$>45$ & \multicolumn{2}{|c|}{} \\
\hline Mean \pm SD & 5 & $30 \pm 8.09$ \\
\hline Educational level & 9 & 10.0 \\
Illiterate & 12 & 18.0 \\
Preparatory & 24 & 24.0 \\
secondary & 48.0 \\
University & 18 & 36.0 \\
\hline Occupation & 32 & 64.0 \\
Working & \\
House wife &
\end{tabular}




\begin{tabular}{|l|c|c||}
\hline Resident area & 10 & 20.0 \\
Rural & 40 & 80.0 \\
Urban & & \\
\hline Family type & 16 & 32.0 \\
Extended & 34 & 68.0 \\
Nuclear & & \\
\hline Family number & 11 & 22.0 \\
3-4 & 25 & 50.0 \\
$4-5$ & 14 & 28.0 \\
\hline 5 & 10 & 20.0 \\
\hline Income & 33 & 66.0 \\
Low (>1000P) & 6 & 12.0 \\
Intermediate(1000- 2000P) & 15 & 30.0 \\
Good(<2000P) & 35 & 70.0 \\
\hline Consanguinity & 9 & 18.0 \\
Yes & 41 & 82.0 \\
no & & \\
\hline Family history of Autism & Positive & \\
Negative & & \\
\hline
\end{tabular}

Table (2): Percentage of autistic children according to their sociodemographic characteristics.

\begin{tabular}{|c|c|c|}
\hline Children characteristics & No & $\%$ \\
\hline $\begin{array}{l}\text { Age } \\
4->6 \\
6->10 \\
10-12\end{array}$ & $\begin{array}{c}26 \\
17 \\
7\end{array}$ & $\begin{array}{c}52.0 \\
34.0 \\
14\end{array}$ \\
\hline Mean \pm SD & \multicolumn{2}{|c|}{$6.28 \pm 2.48$} \\
\hline $\begin{array}{l}\text { Gender } \\
\text { male } \\
\text { Female }\end{array}$ & $\begin{array}{l}37 \\
13\end{array}$ & $\begin{array}{l}74.0 \\
26.0\end{array}$ \\
\hline $\begin{array}{l}\text { Birth order } \\
\text { First } \\
\text { Second } \\
\text { Third } \\
\text { Fourth } \\
\end{array}$ & $\begin{array}{l}20 \\
16 \\
8 \\
6\end{array}$ & $\begin{array}{l}40.0 \\
32.0 \\
16.0 \\
12.0\end{array}$ \\
\hline $\begin{array}{l}\text { Educational class } \\
\text { Nursery } \\
\text { School age }\end{array}$ & $\begin{array}{l}27 \\
23\end{array}$ & $\begin{array}{l}54.0 \\
46.0\end{array}$ \\
\hline $\begin{array}{l}\text { Age ( in years) when autism discovered } \\
1 \\
2->5 \\
>5 \\
\end{array}$ & $\begin{array}{c}9 \\
36 \\
5\end{array}$ & $\begin{array}{l}18.0 \\
72.0 \\
10.0\end{array}$ \\
\hline $\begin{array}{l}\text { Duration of disease ( in years) } \\
<1 \\
1-5 \\
>5 \\
\end{array}$ & $\begin{array}{c}31 \\
15 \\
4\end{array}$ & $\begin{array}{c}62.0 \\
30.0 \\
8.0\end{array}$ \\
\hline
\end{tabular}




\begin{tabular}{|l|c|c|}
\hline Degree of autism & 18 & 36.0 \\
Mild & 26 & 52.0 \\
Moderate & 6 & 12.0 \\
Sever & & \\
\hline Type of management & 48 & 96.0 \\
- Speech therapy & 24 & 48.0 \\
- Behavioral modification & 16 & 32.0 \\
- Skills improvement & 10 & 20.0 \\
- all of above & & \\
\hline Obstetric and neonatal problems & 14 & 28.0 \\
Pregnancy or delivery problems & 21 & 42.0 \\
Neonatal jaundice & 10 & 20.0 \\
Premature birth & 5 & 10.0 \\
Twins birth & & \\
\hline Development in first 3 years regarding social- & 32 & 64.0 \\
communicative behaviors & 18 & 36.0 \\
Upnormal & & \\
Normal then stopped & \\
\hline
\end{tabular}

Table (3): Effect of the educational training on total score of knowledge of studied mothers

\begin{tabular}{|c|c|c|c|c|c|c|c|c|}
\hline \multirow[t]{2}{*}{$\begin{array}{l}\text { Total Knowledge } \\
\text { of mothers }\end{array}$} & \multicolumn{2}{|c|}{$\begin{array}{l}\text { Before } \\
\text { Program } \\
\text { (I) }\end{array}$} & \multicolumn{2}{|c|}{$\begin{array}{c}\text { After } \\
\text { Program } \\
\text { (II) }\end{array}$} & \multicolumn{2}{|c|}{$\begin{array}{l}\text { 3Months } \\
\text { Post } \\
\text { Program } \\
\text { (III) }\end{array}$} & \multirow[t]{2}{*}{$\mathbf{X}^{2}$} & \multirow[t]{2}{*}{$\mathbf{P}$} \\
\hline & No & $\%$ & No & $\%$ & No & $\%$ & & \\
\hline Poor & 39 & 78 & 3 & 6 & 2 & 4 & \multirow{3}{*}{91.45} & \multirow{3}{*}{$<0.05^{*}$} \\
\hline Average & 9 & 18 & 6 & 12 & 8 & 16 & & \\
\hline Good & 2 & 4 & 41 & 82 & 40 & 80 & & \\
\hline Mean \pm SD & \multicolumn{2}{|c|}{$10.8 \pm 6.7$} & 30. & $=6.2$ & \multicolumn{2}{|c|}{$32.6 \pm 7.2$} & & \\
\hline $\begin{array}{c}\text { F- test } \\
\text { Scheffe test }\end{array}$ & \multicolumn{6}{|c|}{$\begin{array}{c}129.91 \\
\text { I\&II,P*- I\&III,P*- II\&III, P }\end{array}$} & & \\
\hline
\end{tabular}

*Significant $\mathbf{p}<0.05$

Table (4): Effect of educational training on total score of management of autistic children performed by mothers

\begin{tabular}{|c|c|c|c|c|c|c|c|c|}
\hline \multirow[t]{2}{*}{$\begin{array}{c}\text { Total Practices of } \\
\text { mothers }\end{array}$} & \multicolumn{2}{|c|}{$\begin{array}{c}\text { Before } \\
\text { Program }\end{array}$} & \multicolumn{2}{|c|}{$\begin{array}{c}\text { After } \\
\text { Program }\end{array}$} & \multicolumn{2}{|c|}{$\begin{array}{l}\text { 3Months } \\
\text { Post } \\
\text { Program } \\
\end{array}$} & \multirow[t]{2}{*}{$\mathbf{X}^{2}$} & \multirow[t]{2}{*}{$\mathbf{P}$} \\
\hline & No & $\%$ & No & $\%$ & No & $\%$ & & \\
\hline Poor & 31 & 62 & 6 & 12 & 4 & 8 & \multirow{3}{*}{49.1} & \multirow{3}{*}{$<0.05^{*}$} \\
\hline Average & 16 & 32 & 5 & 10 & 9 & 18 & & \\
\hline Good & 3 & 6 & 39 & 78 & 37 & 74 & & \\
\hline \multirow{2}{*}{$\begin{array}{c}\text { Mean } \pm \text { SD } \\
\text { F-test } \\
\text { Scheffe test }\end{array}$} & \multicolumn{2}{|c|}{$71.2 \pm 56.2$} & \multicolumn{2}{|c|}{$162.2 \pm 50.1$} & \multicolumn{2}{|c|}{$159.4 \pm 52.4$} & & \\
\hline & \multicolumn{6}{|c|}{$\begin{array}{c}47.72, \mathrm{p}^{*}<0.05 \\
\end{array}$} & & \\
\hline
\end{tabular}

*Significant p $<0.05$ 
Table (5): Effect of the educational training on the total mean score of mothers' attitudes about autism

\begin{tabular}{||l|c|c|c|c|c||}
\hline \multicolumn{1}{||}{ Mothers' attitudes } & $\begin{array}{c}\text { Before } \\
\text { Program }\end{array}$ & $\begin{array}{c}\text { After } \\
\text { Program }\end{array}$ & $\begin{array}{c}\text { 3Months } \\
\text { Post } \\
\text { Program }\end{array}$ & F & \multirow{2}{*}{ P } \\
\cline { 2 - 7 } & Mean \pm SD & Mean \pm SD & Mean \pm SD & & \\
\hline Natural of disease & $6.72 \pm 6.91$ & $9.06 \pm 6.63$ & $11.40 \pm 5.68$ & 6.62 & $<0.05^{*}$ \\
\hline Family problems & $6.84 \pm 6.01$ & $7.94 \pm 6.20$ & $11.12 \pm 5.54$ & 7.03 & $<0.05^{*}$ \\
\hline Stress feelings & $13.96 \pm 7.02$ & $11.10 \pm 7.21$ & $10.34 \pm 6.99$ & 3.63 & $<0.05^{*}$ \\
\hline
\end{tabular}

*Significant p $<0.05$

Table (6): Effect of the educational training on mothers' competency level regarding total mean score of self efficacy, response and satisfaction

\begin{tabular}{|c|c|c|c|c|c|}
\hline \hline $\begin{array}{c}\text { mothers' competency } \\
\text { level }\end{array}$ & $\begin{array}{c}\text { before } \\
\text { Program }\end{array}$ & $\begin{array}{c}\text { after } \\
\text { Program }\end{array}$ & $\begin{array}{c}\text { 3Months } \\
\text { Post } \\
\text { Program }\end{array}$ & \multirow{2}{*}{ F } & \multirow{2}{*}{ P } \\
\cline { 2 - 6 } & Mean \pm SD & Mean \pm SD & Mean \pm SD & \\
\hline \hline Self efficacy & $10.24 \pm 8.08$ & $21.26 \pm 8.34$ & $19.96 \pm 8.86$ & 25.45 & $<0.05^{*}$ \\
\hline Response & $8.42 \pm 5.69$ & $15.66 \pm 4.63$ & $15.24 \pm 4.71$ & 32.52 & $<0.05^{*}$ \\
\hline Satisfaction & $8.14 \pm 5.84$ & $14.88 \pm 5.61$ & $14.58 \pm 5.98$ & 21.42 & $<0.05^{*}$ \\
\hline
\end{tabular}

\footnotetext{
$*$ Significant p $<0.05$
}

Table (7): Correlation between mothers' knowledge, practices, attitudes and competency level scores regarding autism

\begin{tabular}{|c|c|c|c|c|c|c||}
\hline \multicolumn{7}{|c||}{ Total score of efficacy of care score } \\
\hline & \multicolumn{2}{|c|}{ before Program } & \multicolumn{2}{c||}{ after Program } & \multicolumn{2}{c|}{$\begin{array}{c}\text { 3Months Post } \\
\text { Program }\end{array}$} \\
\cline { 2 - 8 } & $\mathbf{R}$ & $\mathbf{P}$ & $\mathbf{r}$ & $\mathbf{P}$ & $\mathbf{r}$ & $\mathbf{P}$ \\
\hline Knowledge & 0.83 & $<0.05^{*}$ & 0.52 & $<0.05^{*}$ & 0.67 & $<0.05^{*}$ \\
\hline Practices & 0.88 & $<0.05^{*}$ & 0.83 & $<0.05^{*}$ & 0.83 & $<0.05^{*}$ \\
\hline Attitudes & 0.97 & $<0.05^{*}$ & 0.93 & $<0.05^{*}$ & 0.92 & $<0.05^{*}$ \\
\hline \hline
\end{tabular}

*Significant $\mathbf{p}<\mathbf{0 . 0 5}$ 
Table (8): Relationship between the mothers' competency level of care and their sociodemographic characteristic

\begin{tabular}{|c|c|c|c|c|c|c|}
\hline \multirow{3}{*}{\multicolumn{2}{|c|}{$\begin{array}{c}\text { Sociodemographic } \\
\text { characteristics of the } \\
\text { mothers }\end{array}$}} & \multicolumn{3}{|c|}{ Total score of competency level of care score } & \multirow{3}{*}{$\mathbf{F}$} & \multirow{3}{*}{$\mathbf{P}$} \\
\hline & & \multirow{2}{*}{$\begin{array}{c}\text { Before } \\
\text { Program } \\
\text { Mean } \pm \text { SD } \\
\end{array}$} & \multirow{2}{*}{$\begin{array}{c}\text { after } \\
\text { Program } \\
\text { Mean } \pm \text { SD } \\
\end{array}$} & \multirow{2}{*}{$\begin{array}{c}\begin{array}{c}\text { 3Months after } \\
\text { Program }\end{array} \\
\text { Mean } \pm \text { SD } \\
\end{array}$} & & \\
\hline & & & & & & \\
\hline \multirow{3}{*}{ Age (year) } & $20-30$ & $44.08 \pm 7.09$ & $68.00 \pm 1.59$ & $67.16 \pm 2.48$ & 24.13 & $<0.05^{*}$ \\
\hline & $30-40$ & $58.00 \pm 2.23$ & $69.14 \pm 1.46$ & $69.14 \pm 1.57$ & 28.97 & $<0.05^{*}$ \\
\hline & $>40$ & $13.06 \pm 7.77$ & $41.61 \pm 16.54$ & $38.67 \pm 16.42$ & 159.30 & $<0.05 *$ \\
\hline \multirow{4}{*}{$\begin{array}{l}\text { Educational } \\
\text { level }\end{array}$} & Illiterate & $4.20 \pm 0.44$ & $15.60 \pm 2.60$ & $12.60 \pm 2.30$ & 95.73 & $<0.05 *$ \\
\hline & Preparatory & $8.27 \pm 1.34$ & $33.72 \pm 6.88$ & $31.63 \pm 7.58$ & 150.33 & $<0.05 *$ \\
\hline & secondary & $25.00 \pm 10.64$ & $59.19 \pm 7.18$ & $56.19 \pm 8.35$ & 123.99 & $<0.05^{*}$ \\
\hline & University & $54.07 \pm 4.89$ & $69.07 \pm 1.03$ & $69.97 \pm 1.11$ & 7.27 & $<0.05^{*}$ \\
\hline \multirow{2}{*}{ Occupation } & Working & $13.56 \pm 8.15$ & $42.31 \pm 16.7$ & $39.40 \pm 16.67$ & -15.61 & $<0.05^{*}$ \\
\hline & Not working & $50.33 \pm 7.70$ & $68.66 \pm 1.23$ & $68.22 \pm 1.92$ & -6.63 & $<0.05^{*}$ \\
\hline \multirow{2}{*}{ Resident } & Urban & $53.42 \pm 5.28$ & $69.07 \pm 0.99$ & $69.00 \pm 1.10$ & -5.04 & $<0.05^{*}$ \\
\hline & Rural & $16.44 \pm 11.33$ & $45.08 \pm 17.65$ & $42.36 \pm 17.76$ & -11.67 & $<0.05^{*}$ \\
\hline \multirow{3}{*}{$\begin{array}{l}\text { Family } \\
\text { number }\end{array}$} & $3-4$. & $53.42 \pm 5.28$ & $69.01 \pm 0.99$ & $69.00 \pm 1.10$ & 108.63 & $<0.05^{*}$ \\
\hline & $5-6$. & $21.08 \pm 10.61$ & $54.88 \pm 10.11$ & $52.08 \pm 10.22$ & 104.60 & $<0.05^{*}$ \\
\hline & $>6$ & $5.90 \pm 1.81$ & $22.18 \pm 7.73$ & $20.09 \pm 8.47$ & 117.91 & $<0.05^{*}$ \\
\hline \multirow{3}{*}{$\begin{array}{l}\text { Family } \\
\text { income }\end{array}$} & Low & $8.05 \pm 2.96$ & $32.10 \pm 12.46$ & $29.25 \pm 12.28$ & 120.26 & $<0.05^{*}$ \\
\hline & Intermediate & $31.85 \pm 11.81$ & $63.14 \pm 5.45$ & $61.04 \pm 6.71$ & 86.89 & $<0.05^{*}$ \\
\hline & good & $56.66 \pm 3.31$ & $69.11 \pm 1.26$ & $69.11 \pm 1.36$ & 89.75 & $<0.05^{*}$ \\
\hline
\end{tabular}

$*$ Significant $\mathbf{p}<0.05$

Table (9): Relationship between mothers' competency level of care and sociodemographic characteristic of the children

\begin{tabular}{|c|c|c|c|c|c|c|}
\hline \multirow{3}{*}{\multicolumn{2}{|c|}{$\begin{array}{l}\text { Sociodemographic } \\
\text { characteristics of the children }\end{array}$}} & \multicolumn{3}{|c|}{ Total score of efficacy of care score } & \multirow{3}{*}{$\mathbf{F}$} & \multirow{3}{*}{$\mathbf{P}$} \\
\hline & & \multirow{2}{*}{$\begin{array}{c}\text { before } \\
\text { Program } \\
\text { Mean } \pm \text { SD }\end{array}$} & \multirow{2}{*}{$\begin{array}{c}\text { after } \\
\text { Program }\end{array}$} & \multirow{2}{*}{$\begin{array}{c}\begin{array}{c}\text { 3Months after } \\
\text { Program }\end{array} \\
\text { Mean } \pm \text { SD }\end{array}$} & & \\
\hline & & & & & & \\
\hline \multirow{3}{*}{ Child age } & $4->6$ & $10.50 \pm 5.40$ & $37.61 \pm 15.00$ & $34.69 \pm 14.86$ & 156.04 & $<0.05^{*}$ \\
\hline & $6-10$ & $38.88 \pm 10.24$ & $66.35 \pm 2.99$ & $64.88 \pm 4.21$ & 44.44 & $<0.05^{*}$ \\
\hline & $10-12$ & $58.00 \pm 2.23$ & $69.14 \pm 1.46$ & $69.14 \pm 1.57$ & 50.11 & $<0.05^{*}$ \\
\hline \multirow{2}{*}{ Sex } & Male & $52.00 \pm 6.32$ & $68.93 \pm 0.99$ & $68.88 \pm 1.35$ & -5.81 & $<0.05^{*}$ \\
\hline & Female & $14.94 \pm 9.69$ & $43.73 \pm 17.22$ & $40.88 \pm 17.23$ & -13.91 & $<0.05^{*}$ \\
\hline \multirow{4}{*}{ Birth order } & First & $8.05 \pm 2.96$ & $32.10 \pm 12.46$ & $29.25 \pm 12.28$ & 192.03 & $<0.05^{*}$ \\
\hline & Second & $26.93 \pm 8.77$ & $61.31 \pm 4.96$ & $58.62 \pm 5.81$ & 61.56 & $<0.05^{*}$ \\
\hline & Third & $49.37 \pm 2.82$ & $69.00 \pm 0.00$ & $69.00 \pm 0.53$ & 67.15 & $<0.05^{*}$ \\
\hline & Fourth & $58.83 \pm 0.40$ & $69.16 \pm 1.60$ & $69.00 \pm 1.67$ & 16.40 & $<0.05^{*}$ \\
\hline \multirow{3}{*}{$\begin{array}{l}\text { Educational } \\
\text { level }\end{array}$} & Nursery & $10.96 \pm 5.82$ & $38.48 \pm 15.38$ & $35.59 \pm 15.30$ & 136.44 & $<0.05^{*}$ \\
\hline & primary class $1-3$ & $41.61 \pm 10.45$ & $66.94 \pm 2.68$ & $65.77 \pm 4.11$ & 38.98 & $<0.05^{*}$ \\
\hline & primary class $4-6$ & $59.00 \pm 0.00$ & $69.20 \pm 1.78$ & $68.80 \pm 1.78$ & 43.55 & $<0.05^{*}$ \\
\hline \multirow{3}{*}{$\begin{array}{l}\text { Duration of } \\
\text { disability }\end{array}$} & $<1$ & $13.06 \pm 7.77$ & $41.61 \pm 16.54$ & $38.67 \pm 16.42$ & 134.81 & $<0.05^{*}$ \\
\hline & $1-5$ & $46.60 \pm 8.25$ & $68.26 \pm 1.53$ & $67.73 \pm 2.49$ & 24.11 & $<0.05^{*}$ \\
\hline & $>5$ & $59.00 \pm 0.00$ & $69.00 \pm 2.00$ & $68.50 \pm 1.91$ & 28.87 & $<0.05^{*}$ \\
\hline \multirow{3}{*}{$\begin{array}{l}\text { Severity of } \\
\text { the disease }\end{array}$} & Mild & $58.83 \pm 0.40$ & $69.16 \pm 1.60$ & $69.00 \pm 1.67$ & 39.02 & $<0.05^{*}$ \\
\hline & Moderate & $41.62 \pm 9.35$ & $67.12 \pm 2.50$ & $65.93 \pm 3.85$ & 34.34 & $<0.05^{*}$ \\
\hline & Sever & $11.46 \pm 6.29$ & $39.32 \pm 15.73$ & $36.42 \pm 15.66$ & 160.16 & $<0.05^{*}$ \\
\hline
\end{tabular}

$*$ Significant $\mathbf{p}<0.05$ 


\section{Tanta Scientific Nursing Journal}

\section{Discussion}

The current study results showed that nearly two thirds of mothers' age ranged from $25-<35$ years and nearly half of them were highly educated. As well, most of them reside in urban areas. These findings were in accordance with those of Attiya 2006, who found that, age of the mothers ranged between $31-<38$ years, and the majority of them were highly educated and living in urban areas, ${ }^{(22)}$ and nearly two thirds of studied mothers were not working in accordance with study of Brandon, 2007 who mentioned that working mothers raising a child with a disability have less time for work and other activities as socializing and leisure than mothers raising a typical child ${ }^{(23)}$ Mostafa , 2012 also stated that housewives reported that their children displayed more autistic symptoms and externalizing problems than the working mothers. ${ }^{(24)}$

It was found that that most of children with autism are boys. This result was supported by, Hassan 2008, who found that majority of children were boys. ${ }^{(25)}$ The present study result indicated that in most of children, autism was discovered in age $2-<5$. This finding was in accordance with Wong 2007 who mentioned that the autism typically appears in the first 3 years of life. ${ }^{(26)}$ This may be due to the important social self-regulation milestone which emerges in the third year of life, building on first-year milestones and early language development, and the ability to regulate behavior and emotions in response to social cues. The failure to achieve this milestone is relevant to autism, which constitutes the defining characteristic of autism by the age of three. ${ }^{(27)}$ This also may duo to delayed in diagnosis of autism which in accordance with Elsheikh, 2016 who concluded that delayed psychiatric consultations among Egyptians may be attributed to lack of access to services (either because of cost or availability) and lack of awareness among the general Egyptian population ${ }^{(28)}$

The finding of this study showed that the overall knowledge of the majority of the mothers regarding their autistic children care was good after the educational training implementation. This finding is similar to Howyida 2012, who found that the level of mother's knowledge improved immediately after the program implementation, ${ }^{(29)}$ and Case-Smith 2005, reported that Parents desire information about their child and the diagnosis and ask for strategies to improve their child's 
performance or manage difficult behaviors. ${ }^{(30)}$

Results of this study revealed that most of the mothers practice regarding their autistic children care was lacking and improved immediately after the program implementation. In this respect, Volkmar2005, stated that parents typically are active partners in their children's education, They transfer skills learned in the educational program to the home setting and teach their children many behaviors that are best mastered in the home and community ${ }^{(31)}$ and according to Tachechak 2009, the parents should participate in the training for their children because they can use the training procedures to continually practice with their children by themselves at home. ${ }^{(32)}$

The current study has revealed that there was improvement in mothers' attitude after the educational training in which they gained more positive attitude regarding natural of autism and child problems .In accordance with Gupta 2004, we report that families have been successful in developing positive perceptions regarding raising a child with disability. ${ }^{(33)}$ The current study has revealed that more than half of the mothers agreed that having a child with autism causing permanent problem to the family before the training program. This negative attitude significantly improved after training. Faux and Nehring 2007 stated that there is a long-held popular belief that having a child with autism is a universally negative event, leading to long-term parental suffering and negative emotional and psychological sequel for other family members. ${ }^{(34)}$

Most of the mothers before the training reported that autistic child cause so many problems which lead to stress. This negative attitude was improved immediately after training, similar to Mungo, 2007, who stated that Parents were found to experience heightened stress, impaired mental health, self-blame, weakened physical functioning, and tiredness. There are financial strains, stressful experiences with professionals, problems associated with school, ineffective services, unmet needs and concerns for the future. ${ }^{(35)}$ Silva 2012 concluded that parenting stress in autism reaches a level that is four times that of typically developing children and is frequently characterized by the feeling that "at times we cannot cope". ${ }^{(36)}$

According to Bandera 1997, Parental efficacy is defined as the parent's beliefs in his or her ability to influence the child and his or her environment to foster the 
child's development and success. ${ }^{(37)}$ The current study revealed that the majority of the mothers involved in the intervention of their autistic children with professional after the program compared to more than half before the program, also Sofronoff 2002 found that Parents are more likely to engage in these activities if they have the confidence that their behavior will indeed have a positive effect on their children. The mother is seen as an important partner to the professionals working with the child ${ }^{\left({ }^{(3)}\right)}$ This study demonstrated that that there was significant improvement in mothers' responsiveness skills toward their autistic children after the educational program more than before the educational training.

Siller 2002, found that children with autism who had parents with more synchronous or responsive behavior have been reported to achieve superior communication skills compared with children whose parents showed lower levels of responsiveness ${ }^{\left({ }^{39)}\right.}$ Morgan 2004, it is necessary for parents and other caregivers to make every effort to connect with the child i.e. physically touch and eye contact, stimulation, talking, smiling, and being sensitive and responsive are other strategies that parents could use to build attachment with their disabled children ${ }^{(40)}$
This study revealed significant positive correlation between mother's competency level of care provided to their autistic children with their knowledge, practices and attitudes (table 32). This finding was in agreement with Sanders 2005, found that mothers who were more active in seeking information and being proactive in the treatment of the child were found to have a greater knowledge of autism. The mothers who reported being more active in their child's development experienced feeling of higher maternal competency ${ }^{(41)}$

The present study revealed significant relationship between mothers' competency level of care and their sociodemographic characteristics. This is in agreement with Sevigny 2009, who stated Parental competency level is influenced by a wide range of variables, including parent characteristics and child characteristics. $^{(42)}$ The present study also showed significant relationship between mothers' competency level and the characteristics of their children. Mothers who have children with severe autism gain low score in their competency level, similarly Hastings 2002, concluded that autism severity appears to be a significant factor which influences parental selfefficacy. Because autism is a spectrum 
disorder, how it impacts child development is highly variable. Mothers of children with more severe autism report lower self-efficacy than mothers of children with milder symptoms. ${ }^{(43)}$

\section{Conclusions}

Based on the results of the current study, the following can be concluded;

Educational training was effective for mothers to improve their knowledge about autism, increase quality of the practice and care provided to autistic children regarding communication, social interaction , maladaptive behavior, massage, play, motor and physical care, decrease negative attitude and parenting stress related to the impact of autism on the child and family. Educational training significantly influenced over all competency level in which mothers showed high self efficacy, parenting satisfaction and also increase maternal responsiveness toward their autistic children.

\section{Recommendations}

Based on the findings of the current study, the following recommendations were suggested:-

Children with autism should be enrolled in an early intervention program as soon as they are diagnosed
Continuous health education and counseling programs are necessary to improve parenting approaches and coping strategies

Nurses should receive adequate and continuous training courses in children care (physically, emotionally and socially). In order to improve their skills in health education for mothers toward their children care.

Mass media should play a significant role to disseminate the needed information about child health care and increase public awareness about autism

Established localized formal centers and special schools which provide treatment services and education for autistic children More researches are needed to identify most common family problems in the community, and available resources that meet family needs.

\section{References}

1. Fernell, Elisabeth. Early diagnosis of autism and impact on prognosive: a narrative review. Clinical Epidemiology. 2013;5(1): 33-43

2. Centers for Disease Control and Prevention. Prevalence of autism spectrum disorders among children aged 8 years, 11 sites, United States, Mortality and Morbidity Weekly. 2014; 63 (2): 21. 
3. Hafiz M. Study about problem size of autism in Egypt. Pediatric medicine, National Commission for Childhood, Studies and research Forum; 2007

4. Seif Eldin A, Habib D, Noufal A, Farrag S. Use of M-CHAT for a multinational screening of young children with autism in the Arab countries. Int Rev Psychiatry 2008; 20(3): $281-9$

5. Chaste $\mathrm{P}$, Leboyer M. Autism risk factors: genes, environment, and geneenvironment interactions. Dialogues Clin Neurosci 2012 ; 14(3): 281-92.

6. Szatmari P. The causes of autism spectrum disorders. British Medical Journal 2006; 326: 173-74

7. American Psychiatric Association. Diagnostic and Statistical Manual of Mental Disorders 5th ed. Washington: Arlington Co., 2013

8. Romanczyk R, Gillis J. Autism Spectrum Disorders: Identification, Education, and Treatment. 3rd ed. London: Lawrence Erlbaum Co., 2004; 515-35

9. Vismara L, Rogers S. Behavioral treatments in autism spectrum disorders: What do we know? Clin Psychol Rev 2010; 6(1):447-68.

10. Legoff B, Sherman M. Long-term outcome of social skills intervention based on interactive LEGO play. Autism 2011; 1: 317-29.

11. Silva T, Schalock M, Gabrielsen K. Early intervention for autism with a parent-delivered qigong massage program. American Journal of Occupational Therapy 2011;65(5):550-59.

12. Volkmar R, Paul A, Cohen D. Handbook of autism and developmental disorders 3rd ed. Hoboken: Wiley Co, 2005; 21(1):1055-86

13. Dunst C, Dempsey I. Familyprofessional partnerships and parenting competence, confidence and enjoyment. International Journal of Disability, Development and Education 2007; 54: 305-18

14. Kuhn J, Carter A. Maternal selfefficacy and associated parenting cognitions among mothers of children with autism. American Journal of Orthopsychiatry. 2006; 76(4): 564-75

15. Johnston C, Huang E. A measure of parenting satisfaction and efficacy. Journal of Clinical Child Psychology 2000; 18 (2): 167-75

16. Symon J. Expanding Interventions for children with children with autism. Journal of Positive Behaviour Interventions 2011; 7(3): 159-73 
17. Donenberg G, Baker B. The impact of young children with externalizing behaviors on their families. Abnorm Child Psychol 1993; 21(1): 190- 198

18. Abidin RA. Parenting stress index professional manual. 3rd ed. Lutz Florida: Psychological Assessment Resources , 1995

19. Rutter, M, Lord C. Social communication questionnaire. Los Angeles: Western Psychological Services, 2003

20. Johnston C, Huang E. A measure of parenting satisfaction and efficacy. Journal of Clinical Child Psychology 2000; 18 (2): 167-75

21. Ruble L, Willish V. Scial skills group therapy for autism spectrum disorders. Jaurnal of Clinical Case Studies. 2005; 7(2) : 287-300

22. Attiya $O$. The efficiency of training program for parents of autistic children in changing their negative attitudes toward their autistic children. Doctoral Thesis, Psychology Department, Faculty of Arts, Ain Shams University. 2006: 221-30

23. Brandon P. Time away from smelling the roses: where do mothers raising children with disabilities find the time to work? Social Science and Medicine. 2007;65(1):667-79.
24. Mostafa Amr , Sociodemographic factors in Arab children with Autism Spectrum Disorders. The Pan African Medical Journal. 2012;10(1):11604

25. Hassan L. Caregiver's awareness regarding autistic children. Master Thesis, Faculty of Nursing, Community Department, Ain Shams University.2008; 82-5.

26. Wong, A. Nursing Care of Infants and Children. 8th ed. USA: Mosby/Elsevier Co., 2007;1021-22.

27. National Research Council. From Neurons to Neighborhoods: The Science of Early Child Development.1sted.Washington D.C:National Academy Press, 2000

28. Elsheikh E, Kuusikko S, Mattila M, Jussila K. Neuropsychological performance of Finnish and Egyptian children with autism spectrum disorder. Int J Circumpolar Health. 2016, 75: 29681

29. Howyida S, Eman N, Inas H. The effect of educational program on caregivers knowledge and practicing toward their autistic children. Journal of American Science .2012;8 (1):1-10

30. Case-Smith. Occupational therapy for children. 5thed. St.Louis: Mosby/Elsevier Co., 2005; 117-59 
31. Volkmar F, Cohen J, Handbook of autism and pervasive developmental disorders. 2nd ed. New York: Wiley Co., 2005

32. Tachechak C. The initial period of assistance for children with autism, Child Development Institute of the Rajanagarindra, Faculty of Education Chiang Mai University. 2009.

33. Gupta A, Singhal N. Positive perceptions in parents of children with disabilities. Asia Pacific Disability Rehabilitation Journal 2004; 15: 22 - 35

34. Faux A, Nehring W. Special issue on children and adolescents with intellectual and developmental disabilities.Pediatric Nursing. 2007; $22(2): 11-26$

35. Mungo D, Ruta L, Arrigo VG.Impairment of quality of life in parents of children and adolescents with pervasive developmental disorder. Health and Quality of life Outcomes. 2007; 22(5): 20-25

36. Silva L, Schalock M. Autism parenting stress index: initial psychometric evidence. Autism Dev Disord.2002; 42(4):566-74

37. Bandura A. Self-efficacy in changing societies.1st ed. New York: Cambridge University Press, 1997; 1-45

38. Sofronoff K, Farbotko M. The effectiveness of parent management training to increase self-efficacy in parents of children with Asperger syndrome. Autism. 2002; 6;271-86

39. Siller M, Sigman M. The behaviors of parents of children with autism predict the subsequent development of their children's communication. Journal of Autism and Developmental Disorders. 2002; 32: 77-89

40. Morgan L, Goldstein H. Teaching mothers of low socioeconomic status to use decontexualized language during storybook reading. Journal of Early Intervention. 2004; 26(1): 23552

41. Sanders M R, Woolley M L. The relationship between maternal selfefficacy and parenting practices: implications for parent training. Child: Care, Health and Development. 2005; 31: 65-73.

42. Sevigny R, Loutzenhiser L. Predictors of parenting self efficacy in mothers and fathers of toddlers. Child Care, Health and Development.2009; 36: 179-89.

43. Hastings P, Symes M D. Early intensive behavioral intervention for children with autism: parental therapeutic self efficacy. Research in Developmental Disabilities. 2002; 23 